\title{
Recent cannabis use in HIV is associated with reduced inflammatory markers in CSF and blood
}

Ronald J. Ellis, MD, PhD, Scott N. Peterson, PhD, Yueling Li, MD, Rachel Schrier, PhD, Jenny ludicello, PhD, Scott Letendre, MD, Erin Morgan, PhD, Bin Tang, PhD, Igor Grant, MD, and Mariana Cherner, PhD

Neurol Neuroimmunol Neuroinflamm 2020;7:e809. doi:10.1212/NXI.0000000000000809

\section{Abstract}

\section{Objective}

To determine whether cannabis may reduce HIV-related persistent inflammation, we evaluated the relationship of cannabis use in people with HIV (PWH) to inflammatory cytokines in CSF and blood plasma.

\section{Methods}

We measured a panel of proinflammatory cytokines (interleukin [IL]-16, C-reactive protein [CRP], IL-6, interferon gamma-induced protein [IP]-10, soluble CD14, and soluble tumor necrosis factor receptor type II [sTNFRII]) in CSF and blood plasma in PWH and HIVindividuals who did or did not use cannabis at various levels of exposure. Participants in this observational cohort were recruited from community sources and underwent lumbar puncture and phlebotomy. Cannabis use parameters were characterized by self-report based on a semistructured timeline follow-back interview. Cytokines were measured using commercially available immunoassays. Data were analyzed using factor analysis.

\section{Results}

Participants were 35 PWH and 21 HIV- individuals, mean (SD) age 45.4 (14.5) years, 41 cannabis ever users, and 15 never users. PWH and HIV- were not different in recency, cumulative months, grams, or density of cannabis use. A factor analysis using CSF biomarkers yielded a factor loading on CRP, IL-16, and sTNFRII that was significantly associated with recency of cannabis use (more recent use associated with lower factor 1 values, reflecting less inflammation; $r=0.331$ [95\% CI 0.0175, 0.586]). In particular, more recent cannabis use was related to lower IL-16 levels $(r=0.549$ [0.282, 0.737]). Plasma biomarkers yielded a factor loading on sTNFRII and IP-10 that was associated with more recent cannabis use (more recent use related to less inflammation; $r=0.374[0.0660,0.617])$.

\section{Conclusions}

Recent cannabis use was associated with lower levels of inflammatory biomarkers, both in CSF and blood, but in different patterns. These results are consistent with compartmentalization of immune effects of cannabis. The principal active components of cannabis are highly lipid soluble and sequestered in brain tissue; thus, our findings are consistent with specific antineuroinflammatory effects that may benefit HIV neurologic dysfunction.

\author{
Correspondence \\ Dr. Ellis \\ roellis@ucsd.edu
}




\section{Glossary}

ART $=$ antiretroviral therapy; $\mathbf{C B 2 R}=\mathrm{CB} 2$ receptor; $\mathbf{C R P}=\mathrm{C}$-reactive protein; $\mathbf{H A N D}=\mathrm{HIV}$-associated neurologic dysfunction; IL = interleukin; IP = interferon gamma-induced protein; $\mathbf{P W H}=$ people with HIV; $\mathbf{R B C}=$ red blood cell; $\mathbf{T H C}=$ delta-9-tetrahydrocannabinol; TLFBI = timeline follow-back interview; TNFRII = tumor necrosis factor receptor type II.

Despite antiretroviral therapy (ART), HIV-associated neurologic dysfunction (HAND) persists in approximately one-third of people with HIV (PWH). Cannabis use is highly prevalent among PWH compared with people who are HIV-. ${ }^{1,2}$ Previous research has demonstrated that microglia are chronically activated in $\mathrm{PWH}$, reflecting neuroinflammation, and may contribute to HAND. ${ }^{3-5}$ Although numerous studies have evaluated cannabis effects on systemic inflammation and immune activation, ${ }^{6,7}$ no previous studies have reported on cannabis use in relation to CSF inflammatory markers. It is known that expression of interleukin 16 (IL-16) is increased in microglial nodules in HIV encephalitis. Microglia express CB2 receptor (CB2R), a cannabinoid receptor that regulates their activation. ${ }^{8,9}$ In other neuroinflammatory diseases, neutralizing IL-16 reduces demyelination and axonal damage. Cannabis downregulates IL-16 in myeloid cells including microglia. ${ }^{10}$ Given that cannabis may have protective anti-inflammatory effects, is neuroprotective in neurodegenerative disorders (Alzheimer disease and Parkinson disease), and is lipophilic and concentrated 3 to 10 times higher in the brain than in blood, we sought to examine possible links between cannabis use and IL16 as a marker of neuroinflammation in HIV. Cannabis biological effects may differ by sex. ${ }^{11,12}$ Given the potential neuroprotective effects of cannabis and its widespread use in $\mathrm{PWH}$, cannabis could be an intervention to protect against HAND.

We sought to evaluate possible links between cannabis use and biomarkers of neuroinflammation in HIV. Figure 1 illustrates the proposed model of cannabis modulation of HIV-induced microglial activation. We hypothesized that inflammatory biomarkers would be reduced in HIV+ individuals who more recently used cannabis.

\section{Methods}

\section{Participants}

This was a cross-sectional prospective observational cohort study of HIV+ and HIV- individuals recruited from community sources. Inclusion criteria were availability of data on cannabis use. Exclusions were diagnoses of other substance use disorders within the past year, positive urine toxicology for substances of abuse other than cannabis, and presence of an active, major psychiatric or neurologic condition such as schizophrenia or epilepsy.

\section{Standard protocol approvals, registrations, and patient consents}

All participants signed an institutional review boardapproved written consent.

\section{Clinical assessment}

All participants underwent a comprehensive neuromedical assessment, blood draw, and lumbar puncture. Parameters of lifetime cannabis use were estimated using a semistructured timeline follow-back interview (TLFBI) as previously described. ${ }^{13}$ The TLFBI uses a calendar method to evaluate daily patterns and frequency of substance use over a specified period. It has high retest reliability, convergent and discriminant validity with other measures, agreement with collateral informants' reports of patients' substance use, and agreement with results from patients' urine assays. ${ }^{14}$ Cannabis recency was assessed as self-reported months since last cannabis use. Other cannabis variables assessed included self-reported frequency, density, and cumulative dose.

\section{Laboratory evaluations}

HIV disease was diagnosed by ELISA with Western blot confirmation. Among HIV+ participants, HIV viral load in plasma was measured using reverse transcriptase PCR (Amplicor; Roche Diagnostics, Indianapolis, IN) and deemed undetectable at a lower limit of quantitation of 50 copies $/ \mathrm{mL}$. CD4 was measured by flow cytometry, and nadir $\mathrm{CD} 4$ was assessed by self-report. Biomarkers measured in plasma and CSF by immunoassay were (IL)-16 (Merck Sharp \& Dohme, Rockville, $\mathrm{MD}$, kit \#K151RED; quantitation range CSF and plasma $6.18-2,530 \mathrm{pg} / \mathrm{mL}$ ), C-reactive protein (CRP) (MSD, K151STD; quantitation range CSF and plasma 12.5-195,000

Figure 1 Conceptual model

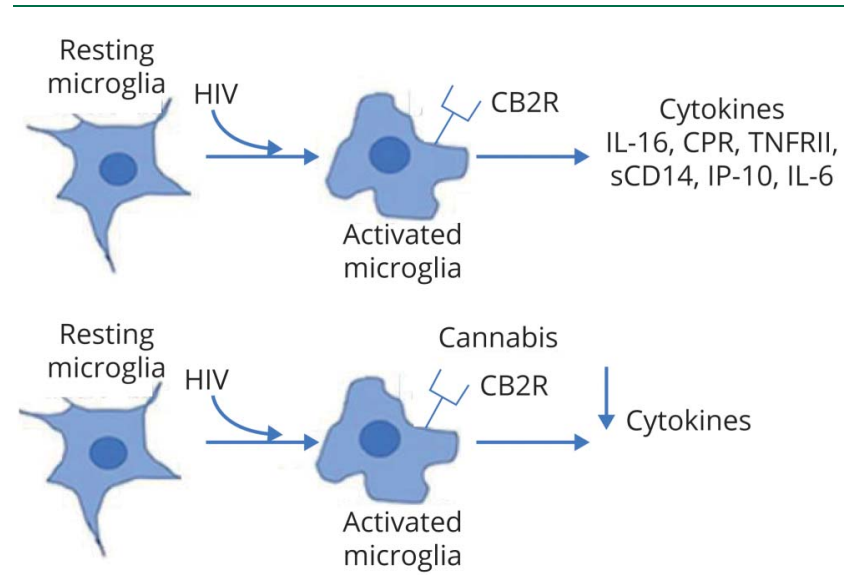

HIV activates resting microglia, which produce cytokines reflecting neuroinflammation. Cannabis (especially $\mathrm{THC}$ ) acts as a ligand for the endocannabinoid receptor $\mathrm{CB} 2$, reducing neuroinflammation. $\mathrm{CB} 2 \mathrm{R}=$ cannabinoid receptor type $2 ; \mathrm{CRP}=\mathrm{C}$-reactive protein; $\mathrm{IL}=$ interleukin; $\mathrm{IP}=$ interferon gamma-induced protein; THC = delta-9-tetrahydrocannabinol; TNFRII = tumor necrosis factor receptor type II. 
Table 1 Participant demographic and clinical characteristics by HIV serostatus

\begin{tabular}{llll}
\hline & HIV - & HIV+ & $\boldsymbol{p}$ \\
\hline $\mathbf{N}$ & 21 & 35 & \\
\hline Age, $\mathbf{y}$ (mean \pm SD) & $42.7(14.2)$ & $47(14.7)$ & 0.28 \\
\hline Education, $\mathbf{y}($ mean \pm SD) & $13.4(2.8)$ & $13.7(2.6)$ & 0.68 \\
\hline Female sex (N, \%) & $7(33 \%)$ & $3(9 \%)$ & 0.02 \\
\hline Non-Hispanic white (N, \%) & $10(47 \%)$ & $10(37 \%)$ & 0.15 \\
\hline CD4 nadir (median, IQR) & - & $278(280,535)$ & - \\
\hline Current CD4 (median, IQR) & - & $699(494,935)$ & - \\
\hline
\end{tabular}

Groups were similar except with respect to sex, with more women in the HIV- group.

pg/mL), IL-6 (MSD K15049D; quantitation range CSF 0.183-749 $\mathrm{pg} / \mathrm{mL}$; plasma $3.2-10,000 \mathrm{pg} / \mathrm{mL})$, interferon gamma-induced protein (IP)-10 (MSD, K15047D; quantitation range CSF IP-10 and plasma $3.2-10,000 \mathrm{pg} / \mathrm{mL}$ ), soluble (s) CD 14 (R\&D, Minneapolis, MN, kit \#DC140; quantitation range CSF and plasma $250-16,000 \mathrm{pg} / \mathrm{mL}$ ), and soluble tumor necrosis factor receptor type II (TNFRII) (MSD F21ZS-3; quantitation range CSF and plasma $12.2-50,000 \mathrm{pg} / \mathrm{mL}$ ).

\section{Statistical analysis}

HIV and cannabis group differences on background characteristics (i.e., demographics and neuropsychiatric and neuromedical characteristics) were examined using analysis of variance, Wilcoxon/Kruskal-Wallis tests, and $\chi^{2}$ statistics as appropriate. Except for CSF IL-16 and TNFRII and plasma soluble $\mathrm{CD} 14, \log _{10}$ transformation of all of the other cytokine measures improved their fit to a normal distribution, and the transformed values were used in analyses. To determine the combined effects of HIV and cannabis on CSF and plasma IL16 levels, multivariable linear regression analyses modeled IL16 as a function of HIV, cannabis use, and their interaction. Follow-up comparisons examined pairwise group differences in IL-16 levels with correction for multiple comparisons using
Tukey Honest Significant Difference tests. Factor analysis was performed in CSF and plasma separately to identify underlying factors that explain correlations among cytokines measured as described above. The first 3 factors were chosen based on the criterion of eigenvalues greater than 1 . Each factor includes the cytokines with loading (correlation, $r$ ) value at least 0.30 . We used multivariable linear regression models to test the interaction effect between HIV status and cannabis recency on CSF factors 1-3. In the absence of the interaction effect, additive effects were tested. In addition, simple linear models were used to regress age, current $\mathrm{CD} 4$, and cannabis recency on CSF factor 1 , and then the relationship of CSF factor 1 with cannabis recency was adjusted for age using multivariable regression. Finally, the correlation between plasma factor 2 and cannabis recency was assessed with Pearson correlation. Sensitivity analyses were conducted on the subset of participants who were virally suppressed. All analyses were conducted using JMP Pro version 14.0.0 (JMP, Version 12.0.1.; SAS Institute Inc., Cary, NC, 2018).

\section{Data availability}

Data will be made available on request.

\section{Results}

Participants were $35 \mathrm{PWH}$ and $21 \mathrm{HIV}$ - individuals, mean (SD) age 45.4 (14.5) years, 41 cannabis ever users, and 15 never users. PLWH had a mean CD4 of 699; 94\% took ART, and $86 \%$ were virologically suppressed. Demographics and clinical characteristics by HIV serostatus are summarized in table 1 . Recency of cannabis use was recorded as a continuous variable (median 10 months; interquartile range [IQR] 1-61 months; range 0.03-414 months). Among users, the route of administration was smoked, and participants did not know the specific formulation (delta-9-tetrahydrocannabinol [THC] vs cannabidiol content); the median grams per day over the last 30 days was 0.5 (IQR $0.125,0.75$ ). The percent with a lifetime history of any substance abuse was $41 \%$, with the majority of this being alcohol (38.6\%). Only $8 \%$ had a lifetime history of cannabis abuse or dependence. Cannabis ever users did not

Table 2 Plasma vs CSF correlations for each of the biomarkers

\begin{tabular}{llll}
\hline Variable & By variable & Correlation & $95 \%$ Cl \\
\hline $\log _{10}$ plasma IL-16 & CSF IL-16 (pg/mL) & 0.239 & $-0.0473,0.455$ \\
\hline $\log _{10}$ (plasma CRP) & $\log _{10}(C S F C R P)$ & 0.808 & $0.692,0.883$ \\
\hline $\log _{10}$ (plasma IL-6) & $\log _{10}(C S F ~ I L-6)$ & -0.069 & $-0.326,0.198$ \\
\hline $\log _{10}$ (plasma IP-10) & $\log _{10}(C S F ~ I P-10)$ & 0.287 & $0.0258,0.511$ \\
\hline Plasma sCD14 & $\log _{10}(C S F ~ S C D 14)$ & 0.198 & $-0.0685,0.438$ \\
\hline $\log _{10}$ (plasma sTNFRII) & CSF STNFRII & 0.311 & $0.0529,0.531$ \\
\hline
\end{tabular}

Abbreviations: $C R P=C$-reactive protein; IL = interleukin; IP-10 = interferon gamma-induced protein 10; sCD14 = soluble CD14.

Correlations were significant (higher plasma associated with higher CSF) for CRP, IP-10, and STNFRII, but not for the other 3 biomarkers. 
Table 3 Factor loadings of the CSF and plasma factors

\begin{tabular}{llllll}
\hline & CRP & IL-16 & IL-6 & IP-10 & STNFRII \\
\hline CSF factor 1 & 0.955 & 0.398 & & 0.332 & 0.694 \\
\hline CSF factor 2 & & 0.453 & 0.333 & 0.432 & 0.707 \\
\hline CSF factor 3 & & & & 0.487 \\
\hline Plasma factor 1 & 0.811 & 0.425 & 0.746 & 0.346 & 0.954 \\
\hline Plasma factor 2 & & & & 0.961
\end{tabular}

Abbreviations: CRP = C-reactive protein; IL = interleukin; IP-10 = interferon gamma-induced protein 10; sCD14 = soluble CD14.

differ from never users on age $(45.3 \pm 12.8$ vs $45.7 \pm 18.9$ years; $p=0.928)$, female sex ( $20 \%$ vs $17.1 \%)$, or non-Hispanic white ethnicity (46.7\% vs $39.0 \%)$. PWH and HIV- were not different in recency, cumulative months, grams, or density of use. Months since last use was unrelated to current and nadir CD4 $(p=0.15$ and 0.43 , respectively). Older participants had more months since last cannabis use than younger. Months since last use was unrelated to race/ethnicity $(p=0.37)$. Men and women did not differ with respect to months since last cannabis use ( $67.8 \pm 127$ vs $70.2 \pm 111)$. Four individuals tested positive on a urine drug screen for cannabis.

Although in most cases, $\mathrm{PWH}$ had higher levels of biomarkers of inflammation than HIV- individuals, these differences reached significance only for IP- 10 (for CSF, $753 \pm 430$ vs $493 \pm 435$; and for plasma, $588 \pm 349$ vs $367 \pm 215$ ). Table 2 shows correlations between plasma and CSF levels of individual biomarkers. Notably, plasma-CSF correlations were generally modest or nonsignificant, except for CRP $(\mathrm{r}=0.808[0.692,0.883])$.

\section{Factor analysis}

Separate factor analyses were performed for CSF and plasma biomarkers to reduce relatively large number of individual biomarkers into a fewer number of dimensions for analysis. Table 3 shows the factor loadings for each of the resulting factors. Levels of all factors were nonsignificantly higher in PWH than in HIV-.

\section{Cannabis recency and CSF factors}

More recent cannabis use was significantly associated with lower CSF factor 1 values $(\mathrm{r}=0.331$; 95\% CI $0.0175,0.586$; figure 2) and with lower plasma factor 2 values ( $\mathrm{r}=0.374 ; 95 \%$ CI 0.0660, 0.617; figure 3A). Among 15 individuals who had never used cannabis, CSF factor 2 levels were higher than the 41 who had ever used cannabis $(0.138 \pm 0.819$ vs $-0.051 \pm$ 0.765). Evaluating the individual components of CSF factor 1 , more recent cannabis use was related to lower CSF CRP and IL-16 levels $(\mathrm{r}=0.336$ [95\% CI 0.0223, 0.589] and $\mathrm{r}=0.549$ [0.282, 0.737], but not sTNFRII $(\mathrm{r}=0.080[-0.241,0.386]$ (figure 3, A-C). Older age was associated with higher CSF CRP $(r=0.504[0.278,0.677])$, but not IL-16 $(r=0.0633$ $[-0.203,0.321])$. After accounting for age, recency of cannabis use was no longer significantly correlated with CSF CRP ( $p=$ 0.247). In a multivariate model with HIV and cannabis recency as independent variables, HIV $\times$ cannabis recency interaction was not significant, indicating that the cannabis recency effect was not different in PWH than in HIV- participants. Viral loads were detectable in 5 participants. In a multivariable model including CSF factor 1 and viral load detectability, the latter was nonsignificant $(p=0.631)$. CSF factor 1 was not associated with cumulative duration, quantity, or density of cannabis use. Higher CSF factor 1 was significantly associated with older age $(\mathrm{r}=0.414[0.169,0.610])$ and higher current CD4 $(\mathrm{r}=0.338$ $[0.00514,0.603]$. In a multivariable regression, after adjusting for age, the relationship between CSF factor 1 and cannabis recency was no longer significant $(p=0.227)$. CD4 did not reach significance in a multivariable model $(p=0.167)$. CSF factors 2 and 3 were not related to cannabis use.

Figure 2 More recent cannabis use correlated with lower CSF factor 1 (indicating reduced CRP, IL-16, and STNFRII)

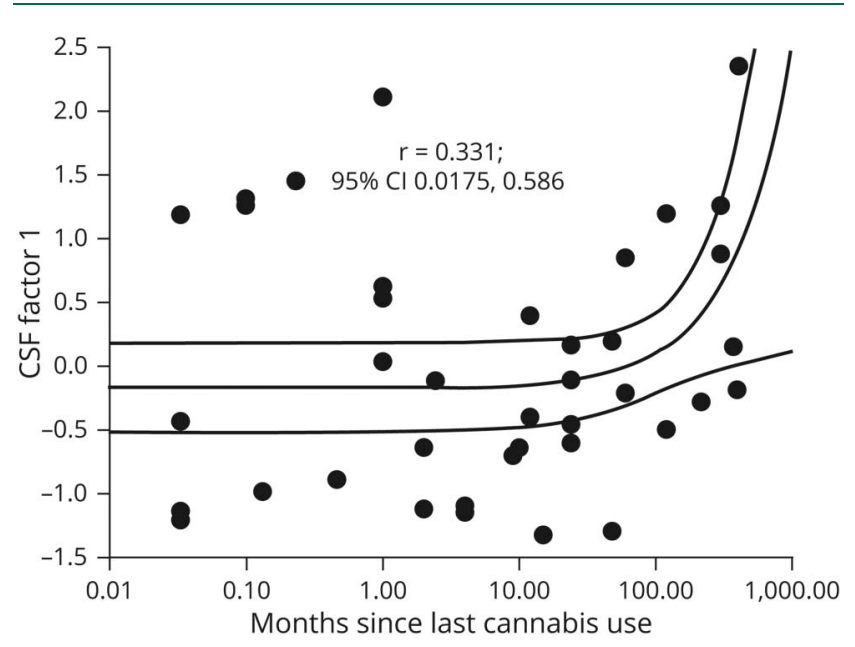

A factor analysis was performed on the 6 CSF markers CRP, IL-16, sTNFRII, SCD14, IP-10, and IL-6. Only factor 1 was associated with recency of cannabis use. The Pearson correlation coefficient and its $95 \% \mathrm{Cl}$ are shown. Note log arithmic time scale. $\mathrm{N}=41$ ever used cannabis. CRP = C-reactive protein; IL = interleukin; IP = interferon gamma-induced protein; $\mathrm{PWH}=$ people with HIV. 
Figure $3(\mathrm{~A}-\mathrm{C}$ ) More recent cannabis use correlated with 2 of the components of CSF factor 1, lower CSF CRP, and IL-16, but not with TNFRII levels
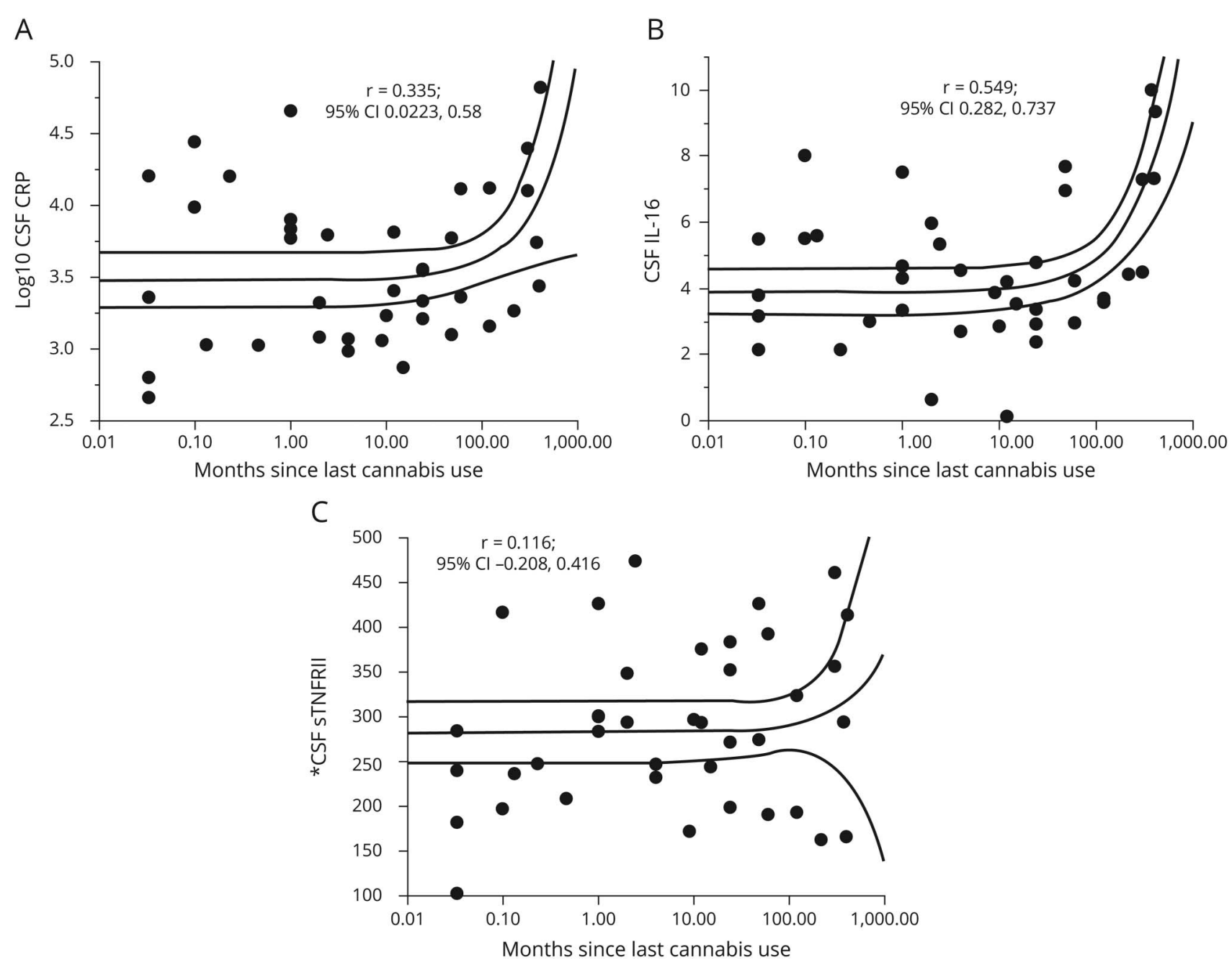

Pearson correlation coefficients and their $95 \% \mathrm{Cls}$ are shown. CRP = C-reactive protein; IL = interleukin; TNFRII = tumor necrosis factor receptor type II.

\section{Cannabis recency and plasma factors}

More recent cannabis use correlated with lower plasma factor 2 (indicating reduced sTNFRII and IP-10; $\mathrm{r}=0.374$ [0.0660, 0.617]; figure 4). Higher plasma factor 1 levels were associated with older age $r=0.381(0.132,0.586)$, but age was unrelated to the other 2 factors. Age did not influence the relationship between factor 1 and recency of cannabis use. Lower nadir CD4 was related to higher plasma factor $2(\mathrm{r}=-0.425[-0.664,-0.107])$. In a multivariable model containing both cannabis use recency and nadir CD4, neither variable reached significance. No other demographic or clinical variables were significantly related to plasma factor 2 .

Table 4 shows Spearman correlations between CSF and plasma factors and their 95\% CIs. With the exception of CSF factor 1 and plasma factor 1 , the factors were independent from one another.
To evaluate for possible confounding by blood plasma contamination of CSF, we used the following approach. First, we calculated the correlations between CSF biomarkers and CSF red blood cell (RBC) count, a marker of blood contamination. Blood contamination would be particularly significant in the case where plasma biomarker levels were much higher than those for CSF. For example, plasma CRP levels were, on average, 1000-fold higher than CSF levels. Although $\log _{10}$ CSF and $\log _{10}$ plasma CRP levels were significantly correlated $(\mathrm{r}=0.808$ [0.692, 0.883]), CSF CRP levels were not associated with CSF RBC ( $\mathrm{r}=$ $-0.00473[-0.267,0.258])$, indicating that the correlation between CSF and blood was not attributable to blood contamination. With the exception of IL-6 $(r=0.443[0.204,0.632])$, CSF biomarker levels were not correlated with CSF RBC counts ( $p s$ > 0.10 ). None of the CSF factor scores was significantly associated with CSF RBC. Despite the significant correlation of $\log _{10}$ CSF $\mathrm{IL}-6$ with CSF RBC, $\log _{10}$ CSF and plasma IL-16 levels were uncorrelated $(\mathrm{r}=0.218[-0.0473,0.455])$. 

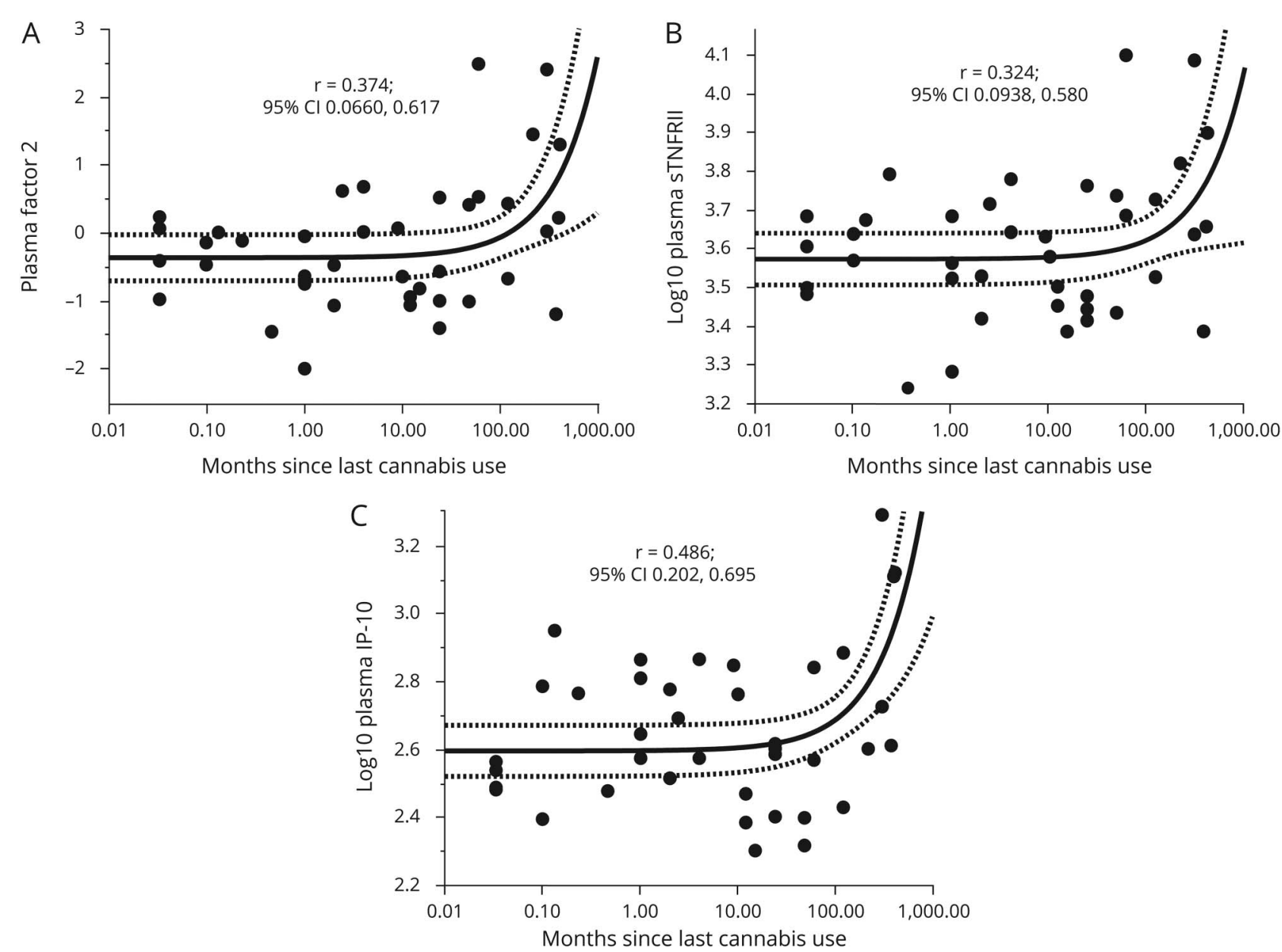

Pearson correlation coefficients and their $95 \% \mathrm{Cl}$ are shown for the plasma factor 2 and for its individual components, sTNFRII and IP-10. IP $=$ interferon gamma-induced protein.

\section{Discussion}

We found that recent cannabis use was associated with reduced levels of a factor loading on IL-16, CRP, and sTNFRII, reflecting reduced neuroinflammation. IL-16, originally called lymphocyte chemoattractant factor, ${ }^{15}$ has been shown to recruit and activate many cells expressing the CD4 molecule, including monocytes, eosinophils, and dendritic cells. ${ }^{16}$ It stimulates the production of proinflammatory cytokines by human monocytes. ${ }^{17} \mathrm{IL}-16$ is unusual among the cytokines because it engages the $\mathrm{CD} 4$ molecule as its receptor instead of a unique IL-16R. Thus, although IL-16 can block HIV cell entry, it nevertheless remains a proinflammatory cytokine. In particular, because activated microglia express IL-16, ${ }^{18}$ our findings suggest reduced microglial activation with recent exposure to cannabis. In addition, $\mathrm{IL}-16$ is an endogenous ligand for the CD4 molecule (a receptor for HIV) and is known for its chemotactic and anti-HIV-1 activities. ${ }^{19}$ CRP is a well-known acute phase reactant. Although CRP expression is largely hepatic, it is also expressed by multiple cells of the CNS, particularly during neuroinflammation, and CNS-specific expression of CRP associates with more severe disease. ${ }^{20}$ sTNFRII (also known as p75) is a receptor for TNF- $\alpha$ and indicates a regulatory response to increased inflammation. Elevated CSF levels of sTNFRII were significantly correlated with worse cognition. Thus, the 3 components of the factor we found to be associated with cannabis recency are involved in the inflammatory response in the CNS.

Although CB1 receptors are the principal type found in the CNS and account for the psychoactive effects of ligands such as THC, CB2Rs also are expressed in the CNS of humans and many animal species. ${ }^{7,21,22}$ In humans, the bulk of CB2R expression is by microglia and THP- 1 cells (a spontaneously immortalized monocyte-like cell line), ${ }^{23}$ as well as astrocytes, ${ }^{24}$ consistent with a role in inflammation. Both in vitro studies and animal models show that CB2R is anti-inflammatory and may be part of the general neuroprotective action of the endocannabinoid system by decreasing glial reactivity. ${ }^{25}$ Both natural and synthetic cannabinoids have been demonstrated to be neuroprotective after various types of CNS insults, such as stroke. ${ }^{26}$

Although numerous studies have evaluated cannabis effects on systemic inflammation and immune activation in $\mathrm{HIV}^{6}$ no 
Table 4 Spearman correlations between CSF and plasma factors and their 95\% Cls

\begin{tabular}{|c|c|c|c|c|}
\hline Variable & By variable & Correlation & Lower $95 \%$ & Upper $95 \%$ \\
\hline Plasma factor 1 & CSF factor 1 & 0.788 & 0.663 & 0.870 \\
\hline Plasma factor 1 & CSF factor 2 & -0.111 & -0.364 & 0.156 \\
\hline Plasma factor 1 & CSF factor 3 & 0.0828 & -0.184 & 0.338 \\
\hline Plasma factor 2 & CSF factor 1 & 0.139 & -0.129 & 0.388 \\
\hline Plasma factor 2 & CSF factor 2 & 0.158 & -0.110 & 0.404 \\
\hline Plasma factor 2 & CSF factor 3 & 0.218 & -0.0477 & 0.455 \\
\hline Plasma factor 3 & CSF factor 1 & 0.150 & -0.117 & 0.397 \\
\hline Plasma factor 3 & CSF factor 2 & 0.136 & -0.132 & 0.385 \\
\hline Plasma factor 3 & CSF factor 3 & 0.109 & -0.159 & 0.361 \\
\hline
\end{tabular}

With the exception of CSF factor 1 and plasma factor 1, the factors were independent.

previous studies have reported on cannabis use in relation to CSF soluble markers of inflammation in HIV. Also, it is often difficult to distinguish between heavy and recent cannabis use because heavy users are more likely to have used recently. For example, in 1 study, heavy cannabis users had fewer activated immune cells $\left(\mathrm{CD}^{+}\right.$and $\mathrm{CD}^{+} \mathrm{T}$ cells expressing Class II human leukocyte antigen and CD38 [HLA-DR+CD $\left.38^{+}\right]$) in peripheral blood compared with non-cannabis-using individuals. Heavy cannabis users also had fewer IL-23 and phorbol 12-myristate 13-acetate-induced tumor necrosis factor- $\alpha$-producing antigen-presenting cells ${ }^{27}$ in blood. Complementing these findings, we show that soluble markers of inflammation in blood-specifically sTNFRII, IP-10_also are lower in those who used cannabis. These findings are consistent with another study showing reduced plasma IP-10 in cannabis users. ${ }^{28}$ In another study, cannabis users had lower TNF- $\alpha$ levels than nonusers. ${ }^{29}$

The specific cytokines associated with cannabis use differed for CSF and plasma. This suggests compartmentalization of immune responses between the CNS and systemic compartments. We found a high correlation between CSF and plasma CRP, but not between CSF and plasma levels of the other markers. Previously published evidence indicates that bloodborne CRP can indeed cross the blood-brain barrier. ${ }^{30}$ In addition, cannabinoids may achieve greater concentrations in CNS due to their lipophilicity and longer duration of action due to sequestration in lipid-rich tissues.

Our results have substantial implications for HIV infection. Because immune activation increases HIV target cells and HIV RNA, reduction of immune activation might lower viral load. This is in line with a previous study reporting that cannabis use was associated with lower plasma HIV RNA among recently infected $\mathrm{PWH}^{33}$ and with reports of reduced HIV replication and cellular infection rate in the presence of cannabinoids in vitro. ${ }^{31,32}$ In addition, in a previous longitudinal study of $\mathrm{PWH}$ with well-characterized histories of substance use, we found that exclusive use of cannabis was associated with a faster decay of HIV DNA during suppressive ART. ${ }^{33}$ Thus, cannabis use may reduce the HIV reservoir. ${ }^{34}$

Our study is limited by several considerations. This was a small pilot study and subject to selection bias and omitted variable bias. Self-reported cannabis use is subject to recall and other biases, particularly in clinical settings, where use may have negative legal consequences. In this study, research participants were explicitly informed that all research data would be held in confidence. We did not characterize the composition of cannabis used in this study with respect to cannabidiol (CBD) or THC, and we did not measure THC and CBD in CSF and blood. This is important because in previous reports, $\mathrm{CBD}$ and THC showed varying effects on anti-inflammatory pathways, including nuclear factor kappa-light-chain-enhancer of activated $\mathrm{B}$ cells and interferon-dependent pathways, ${ }^{35}$ and $\mathrm{CBD}$ accounting for the bulk of anti-inflammatory effects.

Future studies should seek to replicate these findings in a larger sample, directly measuring the response of inflammatory markers to cannabis administration in a controlled setting, and characterize the time course of changes. Vaping and smoking may have different effects. CNS inflammatory markers should be evaluated with respect to neuropsychological performance and imaging measures of neuroinflammation such as [18F]N-(2-(2-fluoroethoxy)benzyl)-N-(4-phenoxypyridin3-yl)acetamide. THC, CBD, and endocannabinoids should be measured in CSF and blood. In the future, cannabinoids may be studied as treatments for neuroinflammation in HIV.

\section{Acknowledgment}

The Translational Methamphetamine AIDS Research Center (TMARC) is supported by Center award P50DA026306 from the National Institute on Drug Abuse (NIDA) and is affiliated with the University of California, San Diego (UCSD), the 
Sanford-Burnham Medical Discovery Institute (SBMDI), and the University of California, Irvine (UCI). The TMARC comprises Administrative Coordinating Core (ACC) - Executive Unit: Director - Igor Grant, MD; Co-Directors - Ronald J. Ellis, MD, $\mathrm{PhD}$, Scott L. Letendre, $\mathrm{MD}$, and Cristian L. Achim, MD, $\mathrm{PhD}$; Center Manager - Mariana Cherner, $\mathrm{PhD}$; Associate Center Managers - Erin E. Morgan, $\mathrm{PhD}$, and Jared Young, $\mathrm{PhD}$; Data Management and Information Systems (DMIS) Unit: Ian S. Abramson, $\mathrm{PhD}$ (Unit Chief) and Clint Cushman, BA (Unit Manager); ACC - Statistics Unit: Florin Vaida, $\mathrm{PhD}$ (Unit Chief), Ian S. Abramson, $\mathrm{PhD}$, Bin Tang, $\mathrm{PhD}$, and Anya Umlauf, MS; ACC - Participant Unit: J. Hampton Atkinson, MD (Unit Chief) and Jennifer Marquie-Beck, MPH (Unit Manager); Behavioral Assessment and Medical (BAM) Core - Neuromedical and Laboratory Unit (NLU): Scott L. Letendre, MD (Core Co-Director/NLU Chief) and Ronald J. Ellis, MD, PhD; BAM Core - Neuropsychiatric Unit (NPU): Robert K. Heaton, $\mathrm{PhD}$ (Core Co-Director/NPU Chief), J. Hampton Atkinson, $\mathrm{MD}$, Thomas D. Marcotte, $\mathrm{PhD}$, Erin E. Morgan, $\mathrm{PhD}$, and Matthew Dawson (NPU Manager); Neuroimaging (NI) Core: Gregory G. Brown, $\mathrm{PhD}$ (Core Director), Thomas T. Liu, $\mathrm{PhD}$, Miriam Scadeng, $\mathrm{PhD}$, Christine Fennema-Notestine, $\mathrm{PhD}$, Sarah L. Archibald, MA, John R. Hesselink, MD, Mary Jane Meloy, $\mathrm{PhD}$, and Craig E.L. Stark, PhD; Neuroscience and Animal Models (NAM) Core: Cristian L. Achim, MD, PhD (Core Director), Marcus Kaul, $\mathrm{PhD}$, and Virawudh Soontornniyomkij, $\mathrm{MD}$; Pilot and Developmental (PAD) Core: Mariana Cherner, $\mathrm{PhD}$ (Core Director) and Stuart A. Lipton, $\mathrm{MD}, \mathrm{PhD}$; Project 1: Arpi Minassian, $\mathrm{PhD}$ (Project Director), William Perry, $\mathrm{PhD}$, Mark A. Geyer, $\mathrm{PhD}$, and Jared W. Young, $\mathrm{PhD}$; Project 2: Amanda B. Grethe, $\mathrm{PhD}$ (Project Director) and Susan F. Tapert, $\mathrm{PhD}$; Project 3: Erin E. Morgan, $\mathrm{PhD}$ (Project Director) and Igor Grant, MD; Project 4: Samuel Barnes, PhD (Project Director); Project 5: Marcus Kaul, PhD (Project Director).

\section{Study funding}

No targeted funding reported.

\section{Disclosure}

R.J. Ellis, S.N. Peterson, Y. Li, R. Schrier, J. Iudicello, S. Letendre, E. Morgan, B. Tang, I. Grant, and M. Cherner report no disclosures. Go to Neurology.org/NN for full disclosures.

\section{Publication history}

Received by Neurology: Neuroimmunology \& Neuroinflammation December 22, 2019. Accepted in final form May 15, 2020.

Appendix Authors

\begin{tabular}{lll}
\hline Name & Location & Contribution \\
\hline $\begin{array}{l}\text { Ronald J. } \\
\text { Ellis, MD, } \\
\text { PhD }\end{array}$ & $\begin{array}{l}\text { University of California, } \\
\text { San Diego }\end{array}$ & $\begin{array}{l}\text { Designed and conceptualized the } \\
\text { study; analyzed the data; and } \\
\text { drafted the manuscript for } \\
\text { intellectual content }\end{array}$ \\
\hline $\begin{array}{l}\text { Scott N. } \\
\text { Peterson, } \\
\text { PhD }\end{array}$ & $\begin{array}{l}\text { Sanford Burnham } \\
\text { Prebys Medical } \\
\text { Discovery Institute }\end{array}$ & $\begin{array}{l}\text { Interpreted the data and revised } \\
\text { the manuscript for intellectual } \\
\text { content }\end{array}$ \\
\hline
\end{tabular}

\section{Appendix (continued)}

\begin{tabular}{|c|c|c|}
\hline Name & Location & Contribution \\
\hline $\begin{array}{l}\text { Yueling Li, } \\
\text { MD }\end{array}$ & $\begin{array}{l}\text { University of California, } \\
\text { San Diego }\end{array}$ & $\begin{array}{l}\text { Interpreted the data and revised } \\
\text { the manuscript for intellectual } \\
\text { content }\end{array}$ \\
\hline $\begin{array}{l}\text { Rachel } \\
\text { Schrier, } \\
\text { PhD }\end{array}$ & $\begin{array}{l}\text { University of California, } \\
\text { San Diego }\end{array}$ & $\begin{array}{l}\text { Interpreted the data and revised } \\
\text { the manuscript for intellectual } \\
\text { content }\end{array}$ \\
\hline $\begin{array}{l}\text { Jenny } \\
\text { ludicello, } \\
\text { PhD }\end{array}$ & $\begin{array}{l}\text { University of California, } \\
\text { San Diego }\end{array}$ & $\begin{array}{l}\text { Interpreted the data and revised } \\
\text { the manuscript for intellectual } \\
\text { content }\end{array}$ \\
\hline $\begin{array}{l}\text { Scott } \\
\text { Letendre, } \\
\text { MD }\end{array}$ & $\begin{array}{l}\text { University of California, } \\
\text { San Diego }\end{array}$ & $\begin{array}{l}\text { Major role in the acquisition of } \\
\text { data }\end{array}$ \\
\hline $\begin{array}{l}\text { Erin } \\
\text { Morgan, } \\
\text { PhD }\end{array}$ & $\begin{array}{l}\text { University of California, } \\
\text { San Diego }\end{array}$ & $\begin{array}{l}\text { Interpreted the data and revised } \\
\text { the manuscript for intellectual } \\
\text { content }\end{array}$ \\
\hline $\begin{array}{l}\text { Bin Tang, } \\
\text { PhD }\end{array}$ & $\begin{array}{l}\text { University of California, } \\
\text { San Diego }\end{array}$ & Performed statistical analyses \\
\hline $\begin{array}{l}\text { Igor } \\
\text { Grant, MD }\end{array}$ & $\begin{array}{l}\text { University of California, } \\
\text { San Diego }\end{array}$ & $\begin{array}{l}\text { Interpreted the data and revised } \\
\text { the manuscript for intellectual } \\
\text { content }\end{array}$ \\
\hline $\begin{array}{l}\text { Mariana } \\
\text { Cherner, } \\
\text { PhD }\end{array}$ & $\begin{array}{l}\text { University of California, } \\
\text { San Diego }\end{array}$ & $\begin{array}{l}\text { Interpreted the data and revised } \\
\text { the manuscript for intellectual } \\
\text { content }\end{array}$ \\
\hline
\end{tabular}

\section{References}

1. Anthony JC, Lopez-Quintero C, Alshaarawy O. Cannabis epidemiology: a selective review. Curr Pharm Des 2017;22:6340-6352.

2. Pacek LR, Towe SL, Hobkirk AL, Nash D, Goodwin RD. Frequency of cannabis use and medical cannabis use among persons living with HIV in the United States: findings from a nationally representative sample. AIDS Educ Prev 2018;30: 169-181.

3. Wu B, Huang Y, Braun AL, et al. Glutaminase-containing microvesicles from HIV-1infected macrophages and immune-activated microglia induce neurotoxicity. Mol Neurodegener 2015;10:61.

4. Chen NC, Partridge AT, Sell C, Torres C, Martin-Garcia J. Fate of microglia during HIV-1 infection: from activation to senescence? Glia 2017;65:431-446.

5. Periyasamy P, Thangaraj A, Guo ML, Hu G, Callen S, Buch S. Epigenetic promoter DNA methylation of miR-124 promotes HIV-1 tat-mediated microglial activation via MECP2-STAT3 Axis. J Neurosci 2018;38:5367-5383.

6. Klein TW. Cannabinoid-based drugs as anti-inflammatory therapeutics. Nat Rev Immunol 2005;5:400.

7. Maresz K, Carrier EJ, Ponomarev ED, Hillard CJ, Dittel BN. Modulation of the cannabinoid CB2 receptor in microglial cells in response to inflammatory stimuli. J Neurochem 2005;95:437-445.

8. Carlisle SJ, Marciano-Cabral F, Staab A, Ludwick C, Cabral GA. Differential expression of the $\mathrm{CB} 2$ cannabinoid receptor by rodent macrophages and macrophagelike cells in relation to cell activation. Int Immunopharmacol 2002;2:69-82.

9. Guida F, Luongo L, Boccella S, et al. Palmitoylethanolamide induces microglia changes associated with increased migration and phagocytic activity: involvement of the CB2 receptor. Sci Rep 2017;7:375.

10. Nair MP, Figueroa G, Casteleiro G, Munoz K, Agudelo M. Alcohol versus cannabinoids: a review of their opposite neuro-immunomodulatory effects and future therapeutic potentials. J Alcohol Drug Depend 2015;3:184.

11. Fattore L, Fratta W. How important are sex differences in cannabinoid action? Br J Pharmacol 2010;160:544-548.

12. Struik D, Sanna F, Fattore L. The modulating role of sex and anabolic-androgenic steroid hormones in cannabinoid sensitivity. Front Behav Neurosci 2018;12:249.

13. Sobell LC, Sobell MB. Timeline Followback User's Guide: A Calendar Method for Assessing Alcohol and Drug Use. Toronto: Addiction Research Foundation; 1996.

14. Fals-Stewart W, O'Farrell TJ, Freitas TT, McFarlin SK, Rutigliano P. The timeline followback reports of psychoactive substance use by drug-abusing patients: psychometric properties. J Consult Clin Psychol 2000;68:134-144.

15. Cruikshank W, Center DM. Modulation of lymphocyte migration by human lymphokines. II. Purification of a lymphotactic factor (LCF). J Immunol 1982;128: 2569-2574.

16. Cruikshank WW, Kornfeld H, Center DM. Interleukin-16. J Leukoc Biol 2000;67: 757-766. 
17. Mathy NL, Scheuer W, Lanzendorfer M, et al. Interleukin-16 stimulates the expression and production of pro-inflammatory cytokines by human monocytes. Immunology 2000;100:63-69.

18. Liebrich M, Guo LH, Schluesener HJ, et al. Expression of interleukin-16 by tumorassociated macrophages/activated microglia in high-grade astrocytic brain tumors. Arch Immunol Ther Exp (Warsz) 2007;55:41-47.

19. Zhao ML, Si Q, Lee SC. IL-16 expression in lymphocytes and microglia in HIV-1 encephalitis. Neuropathol Appl Neurobiol 2004;30:233-242.

20. Wright T, McCrory M, Morgan T, et al. Central nervous system-specific expression of C-reactive protein exacerbates experimental autoimmune encephalomyelitis. (BA3P.202). J Immunol 2014;192(1 suppl):44.8.

21. Benito C, Romero JP, Tolon RM, et al. Cannabinoid CB1 and CB2 receptors and fatty acid amide hydrolase are specific markers of plaque cell subtypes in human multiple sclerosis. J Neurosci 2007;27:2396-2402.

22. Van Sickle MD, Duncan M, Kingsley PJ, et al. Identification and functional characterization of brainstem cannabinoid CB2 receptors. Science 2005;310:329-332.

23. Klegeris A, Bissonnette CJ, McGeer PL. Reduction of human monocytic cell neurotoxicity and cytokine secretion by ligands of the cannabinoid-type CB2 receptor. $\mathrm{Br}$ J Pharmacol 2003;139:775-786.

24. Sheng WS, Hu S, Min X, Cabral GA, Lokensgard JR, Peterson PK. Synthetic can nabinoid WIN55,212-2 inhibits generation of inflammatory mediators by IL-1betastimulated human astrocytes. Glia 2005;49:211-219.

25. Martin-Moreno AM, Reigada D, Ramirez BG, et al. Cannabidiol and other cannabinoids reduce microglial activation in vitro and in vivo: relevance to Alzheimer's disease. Mol Pharmacol 2011;79:964-973.

26. Fernandez-Ruiz J, Moreno-Martet M, Rodriguez-Cueto C, et al. Prospects for cannabinoid therapies in basal ganglia disorders. Br J Pharmacol 2011;163:1365-1378.
27. Manuzak JA, Gott TM, Kirkwood JS, et al. Heavy cannabis use associated with reduction in activated and inflammatory immune cell frequencies in antiretroviral therapy-treated human immunodeficiency virus-infected individuals. Clin Infect Dis 2018;66:1872-1882.

28. Rizzo MD, Crawford RB, Henriquez JE, et al. HIV-infected cannabis users have lower circulating CD16+ monocytes and IFN-gamma-inducible protein 10 levels compared with nonusing HIV patients. AIDS 2018;32:419-429.

29. Keen L II, Turner AD. Differential effects of self-reported lifetime marijuana use on interleukin-1 alpha and tumor necrosis factor in African American adults. J Behav Med 2015;38:527-534.

30. Rajs G, Finzi-Yeheskel Z, Rajs A, Mayer M. C-reactive protein concentrations in cerebral spinal fluid in gram-positive and gram-negative bacterial meningitis. Clin Chem 2002;48:591-592.

31. Costantino CM, Gupta A, Yewdall AW, Dale BM, Devi LA, Chen BK. Cannabinoid receptor 2-mediated attenuation of CXCR4-tropic HIV infection in primary CD4+ T cells. PLoS One 2012;7:e33961.

32. Ramirez SH, Reichenbach NL, Fan S, et al. Attenuation of HIV-1 replication in macrophages by cannabinoid receptor 2 agonists. J Leukoc Biol 2013;93: 801-810.

33. Chaillon A, Nakazawa M, Anderson C, et al. Effect of cannabis use on human immunodeficiency virus DNA during suppressive antiretroviral therapy. Clin Infect Dis 2020;70:140-143.

34. Eisenstein TK, Meissler JJ. Effects of cannabinoids on T-cell function and resistance to infection. J Neuroimmune Pharmacol 2015;10:204-216.

35. Juknat A, Pietr M, Kozela E, et al. Differential transcriptional profiles mediated by exposure to the cannabinoids cannabidiol and Delta9-tetrahydrocannabinol in BV-2 microglial cells. Br J Pharmacol 2012;165:2512-2528. 


\title{
Neurology \\ Neuroimmunology \& Neuroinflammation
}

\author{
Recent cannabis use in HIV is associated with reduced inflammatory markers in CSF \\ and blood \\ Ronald J. Ellis, Scott N. Peterson, Yueling Li, et al. \\ Neurol Neuroimmunol Neuroinflamm 2020;7; \\ DOI 10.1212/NXI.0000000000000809
}

This information is current as of June 17, 2020

\section{Updated Information \& \\ Services}

References

Citations

Subspecialty Collections

Permissions \& Licensing

Reprints including high resolution figures, can be found at:

http://nn.neurology.org/content/7/5/e809.full.html

This article cites 34 articles, 5 of which you can access for free at: http://nn.neurology.org/content/7/5/e809.full.html\#\#ref-list-1

This article has been cited by 2 HighWire-hosted articles: http://nn.neurology.org/content/7/5/e809.full.html\#\#otherarticles

This article, along with others on similar topics, appears in the following collection(s):

Cerebrospinal Fluid

http://nn.neurology.org//cgi/collection/cerebrospinal_fluid

HIV

http://nn.neurology.org//cgi/collection/hiv

Information about reproducing this article in parts (figures,tables) or in its entirety can be found online at:

http://nn.neurology.org/misc/about.xhtml\#permissions

Information about ordering reprints can be found online:

http://nn.neurology.org/misc/addir.xhtml\#reprintsus

Neurol Neuroimmunol Neuroinflamm is an official journal of the American Academy of Neurology.

Published since April 2014, it is an open-access, online-only, continuous publication journal. Copyright

Copyright $\odot 2020$ The Author(s). Published by Wolters Kluwer Health, Inc. on behalf of the American

Academy of Neurology.. All rights reserved. Online ISSN: 2332-7812.

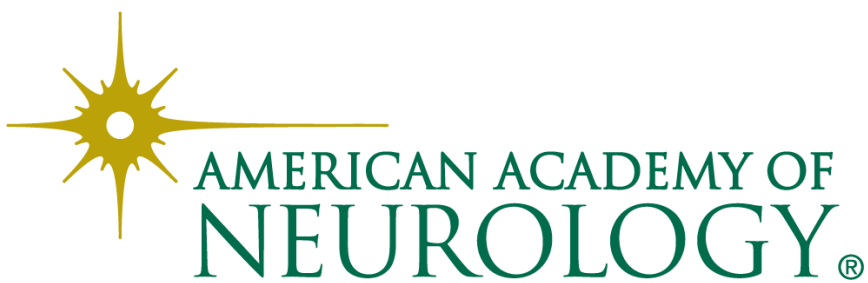

